\title{
Research on the Differences of Apparel Brand Value Perception of the Intellectual 80's Women: A Case Study of Hangzhou
}

\author{
Yiling Zhang ${ }^{1,2}$, Xiangyang Bian $^{1} \&$ Ziying $\mathrm{Yu}^{2}$ \\ ${ }^{1}$ College of Fashion and Design, Donghua University, Shanghai, China \\ ${ }^{2}$ Applied Technical School, Jiaxing University, Jiaxing, China \\ Correspondence: Xiangyang Bian, College of Fashion and Design, Donghua University, Shanghai, No. 1882, \\ West Yan-an Road, 200051, China. Tel: 86-21-6237-3978. E-mail: bianxy@dhu.edu.cn
}

\author{
Received: May 10, $2018 \quad$ Accepted: May 18, $2018 \quad$ Online Published: July 27, 2018 \\ doi:10.5539/ass.v14n8p54 URL: https://doi.org/10.5539/ass.v14n8p54
}

\begin{abstract}
With the hot competition in apparel market, improving customer value has become a key measure for garment enterprises to win. As for the trend of diversification of apparel market demand, this article examines brand value from the perspective of consumers, and investigates attitude of the intellectual 80's women in Hangzhou. Then the results show that the intellectual 80's women are rational in apparel brand consumption. They pay attention to the functionality of garments, the symbolism of brand, the fashion and culture taste, the consumption experience. And according to the results of the partial correlation analysis and T-test, this paper finds that due to the difference of sample characteristics, there are significant differences in the dimensions perceived value.
\end{abstract}

Keywords: perceived value, apparel brand, perceived benefit, perceived cost, the intellectual 80's women

After 1990s, the Chinese market has entered the stage of brand competition after many rounds of competition, such as quality, price and so on. Brand competition is a contest between the brand value. Gardner \& Levy (1955), in his first paper about brand, put forward the idea of "recognizing the nature of brand, that is, brand is not only functional, but also emotional." Lannon \& Copper (1983) persisted in the emotional of brand creation, and made contributions to the research of this subject by using the theory of Anthropology and psychology. Lannon (1994) uses the anthropological theory to demonstrate the brand value added as a symbolic means. This paper will take the perceived value of apparel brand as the breakthrough point. From the three aspects of age, culture and income, investigating the difference of intellectual 80's women's attitude to brand value in Hangzhou, and provide some suggestions for the women's clothing enterprises based on the findings.

\section{The Change of Apparel Brand Value}

Clothing has a universal anthropological significance. It is not only a basic physiological demand, but also an external marker to reflect the social attributes of human society. It is also a symbol of different social civilizations and cultures. It can not only be a life necessities that are easy to produce, but also a luxury product that needs careful preparation and processing. Meanwhile, clothing reflects people's social identity, constructs social structure, and expresses the differences of cultural, racial and gender in different society. Nowadays, with the improvement of living standard and the change of consumption concept, the demand for clothing is gradually developed from the basic demand to the high level of self realization. At this time, the consumer's attention to the value of apparel brand has also changed. In their mind, the clothing purchased is not only a dress, but a special experience and specific performance of self-remoulding. The brand bought is not only a symbol of product quality and brand recognition, but also a representative of the value concept, life attitude, aesthetic taste, personality cultivation, fashion taste, emotional appeal and so on.

\section{Research of Perceived Value}

The original motive force of the emergence and development of the theory of perceived value is to pursue sustainable competitive advantage in the turbulent internal and external environment. In 1954, Drucker first put forward that customers purchase and consume is not just products, but values. In 1990s, Keller proposed customer perceived value equity, namely, the Customer Perceived Value (CPV), which refers to the overall evaluation of the product or service utility after the trade-off between the perceived benefits and perceived cost. $\mathrm{CPV}$ is the subjective cognition of consumers to products and services, which is different from the objective 
value. On the one hand, value is the result of consumers weighing the perceived income and cost, influenced by many factors; on the other hand, the perceived value of consumers varies from person to person, and the value of different consumers to the same product or service is not the same.

In the development of customer value theory, the study of perceived value mainly focuses on three points. The first research focus is the study of the perceived value dimension. The division of perceived value also varies from research perspective. Sheth, Newman \& Gross (1991) proposed five dimensional models: function value, social value, emotional value, situational value, and epistemic value. The model points out which dimensions the customer perceives the "gains and losses" of products, and provides a perfect measurement scale for the subsequent empirical research on perceived value. Lassar, Mittal \& Shaima (1995), based on the quantitative research of customer brand value, divides brand value into five aspects: performance, value, social image, trustworthiness and commitment. Holbrook (1996) divides the consumer perceived value into three main dimensions: Extrinsic versus iIntrinsic; Self- versus other-oriented; Active versus reactive. Parasuraman (1997) uses the quantitative analysis method to subdivide the perceived value into four types: acquisition value, transaction value, usage value and redemption value. Kotler (2000) analyzes the perceived value from two aspects, the total customer value and the total customer cost. Then he subdivides the two of them. The total customer value includes the value of product, service, personnel and image. The total customer cost includes the dimensions of money, time, energy and so on. Sweeny \& Soutar (2001), based on the perceived value framework of Sheth, shows that perceived value has emotional value, social value, functional price value and functional value through empirical study. The second research focus is the research on the driving factors of perceived value. Many scholars believe that perceived value mainly influenced by factors such as products, services and prices. While Indrajit \& Wayne believes that perceived value is driven by value, quality, profits and costs. Gronroos (2000) adds customer relationship as the driving force of perceived value. Tong Xiao \& Jana M. Hawley (2009) discuss the most effective marketing activities in the Chinese apparel market for brand value. The results show that store image, celebrity endorsement, Internet advertising and non price promotion have a positive effect on the brand value of Chinese apparel market, and the regular price promotion will have a negative effect on the brand value. The results of their another study show that brand association and brand loyalty are two important factors of brand value, while brand perceived quality and brand awareness are less influential. Meanwhile, On the basis of brand theory, domestic scholars believe that brand equity is an important driving force for perceived value. Liu Wenbo (2008) points out that experience is of great significance to perceived value. The third research focus is about the study of perceived value affecting decision-making behavior. Monroe \& Shnan (1985) studied the relationship between price, quality, perceived value and purchase intention, and found that consumers decided whether to buy according to the value they perceived. D odds et al. (1991) also found that perceived value had a positive impact on consumers' purchase intention. Recently, many studies have done empirical research on it. Jaehee Jung \& Eun young Sung (2008) analyse three groups of people: American, Korean and Koreans in the United States to evaluate and compare the brand value of garments. At the same time, the influence of cross culture on the purchase intention of brand value was studied. The results showed that among the factors of brand value, American students were significantly higher in brand awareness and brand association than those in the United States and Koreans. For the two Koreans, brand loyalty is the most important factor in brand value. And brand loyalty is positively correlated with brand value and purchase intention.

Generally speaking, the study of customer perceived value is deepening. However, due to the short research time, there are still many problems to be further explored. For example, what is the source of customer perceived value, what value elements are included, what is the customer's understanding, evaluation and selection process, and how the perceived value of the customer changes with the development of the economy and society, especially how to make effective quantitative analysis and empirical research on the perceived value. Therefore, this paper makes a horizontal and vertical comparison between the intellectual 80's woman's attention to the each dimension of perceived value, and then subdivides the domestic 80's woman's apparel market.

\section{The Difference Analysis of Perceived Value to Apparel Brand}

On the basis of the five dimension model proposed by Sheth, through the investigation of the intellectual 80's women, this paper divides the perceived value of apparel brand into two categories: perceived benefit and perceived cost. Perceived benefit is perceived as the consumer's perception of the physical properties, service attributes, and support of the brand products. The perceived cost includes the total cost that the buyer faces when buying and consuming, such as price, acquisition cost, purchase risk, and additional expenses due to purchase. And using qualitative research, the perception income is refined into five dimensions: function value, social value, emotional value, epistemic value and experiential value; perceived cost is divided into two aspects: 
purchase cost and risk, and usage cost. In order to analyze the perceived value of the intellectual 80 's women to apparel brand, and to ensure the reliability and validity of the research scale, this study adopts a high maturity scale which has been used by scholars at home and abroad, and forms a scale to measure the perceived value of the intellectual 80's women to apparel brand. The questionnaire is divided into two parts. The first part is the basic personal information of the respondents, and the second part is the scale of the perceived value. The expression of the importance of the index is expressed by the Likert7-Scale, which is divided into 7 levels. The higher the score, the more reasonable the evaluation index is. A total of 563 questionnaires were sent out, and 540 valid questionnaires were screened. The effective rate of the questionnaires was $95.91 \%$. The proportion of samples at each level is shown in Table 2, Table 3 and Table 4.

\subsection{Analysis of the Importance of Each Dimension of Perceived Value}

Table 1. The statistics of "Fi"

\begin{tabular}{|c|c|c|c|c|c|c|c|}
\hline & $\begin{array}{c}\text { Functional } \\
\text { Value } \\
\text { F1 }\end{array}$ & $\begin{array}{c}\text { Social } \\
\text { Value } \\
\text { F2 }\end{array}$ & $\begin{array}{c}\text { Emotional } \\
\text { Value } \\
\text { F3 }\end{array}$ & $\begin{array}{l}\text { Epistemic } \\
\text { Value } \\
\text { F4 }\end{array}$ & $\begin{array}{c}\text { Experiential } \\
\text { value } \\
\text { F5 }\end{array}$ & $\begin{array}{c}\text { Purchase Cost } \\
\text { and Risk } \\
\text { F6 }\end{array}$ & $\begin{array}{c}\text { Usage } \\
\text { Cost } \\
\text { F7 }\end{array}$ \\
\hline $\mathrm{M}$ & 5.1971 & 4.6210 & 4.0461 & 4.5168 & 4.3250 & 4.4108 & 3.8007 \\
\hline SD & 1.33011 & 1.17170 & 2.30500 & 0.90667 & 1.04839 & 0.87404 & 0.55361 \\
\hline $\mathrm{P}(\mathrm{Fi}>4)$ & 0.8159 & 0.7169 & 0.5080 & 0.7157 & 0.6217 & 0.6808 & 0.3594 \\
\hline
\end{tabular}

According to the statistics, from the perspective of consumer brand value, the order of the relative importance of the seven perceived dimensions of the intellectual 80's women is that: functional value F1 (81.59\%), social value F2 (71.69\%), epistemic value F4 (71.57\%), purchase cost and risk F6 (68.08\%), experiential value F5 (62.17\%), emotional value $\mathrm{F} 3(50.80 \%)$ and usage cost $\mathrm{F} 7$ (35.94\%).

\subsection{The Relationship between Age and Perceived Value}

Individuals at different ages have different needs and psychological awareness. The respondents of this survey are the intellectual 80's women in Hangzhou, although they were born in 1980-1989 years, but there are also large differences in demand, so the age is divided into 5 stages to compare, the table 2 is the proportion of samples of all ages.

Table 2. Proportion of respondents in each age group

\begin{tabular}{cccccc}
\hline Ages & $1980-1981$ & $1982-1983$ & $1984-1985$ & $1986-1987$ & $1988-1989$ \\
\hline Number & 112 & 99 & 110 & 119 & 100 \\
Proportion & $20.74 \%$ & $18.33 \%$ & $20.37 \%$ & $22.04 \%$ & $18.52 \%$ \\
\hline
\end{tabular}

The correlation between age and perceived value was analyzed by SPSS19.0. The following tables are the results of partial correlation analysis between age and customer perceived value. In order to avoid the influence of other personal characteristics, two variables of "cultural level" and "income" were eliminated in the analysis, and the partial correlation analysis of the two variables of "age" and "Fi" was carried out in the double tail test.

As shown in Figure 1, the free degree of the partial correlation coefficient $\mathrm{T}$ is $\mathrm{n}-\mathrm{k}-2=540-2-2=536$. The partial correlation coefficients of "age" and perceived value were $0.3291,0.3443,0.1024,-0.5180,0.1223,0.5407$ and 0.0041 , and the significant probability was $0.012,0.009,0.039,0.009,0.021,0.006$ and 0.063 , indicating that function value and "age" were medium positive correlation, after eliminating the "cultural level" and "income". That is, with the growth of age, the group will pay more attention to functional value.The moderate positive correlation between social value and age, that is, as growth of age, the group will pay more attention to social value. There is a weak correlation between emotional value and age. And there is a strong relationship between epistemic value and age. Negative correlation, that is, as the population grows with age, the more the value of epistemic value is reduced. There is a weak positive correlation between epistemic value and age, that is, the group has a weak trend of increasing the value of experience with the increase of age. There is a significant positive correlation between the purchase cost and the risk and the age, that is, as the age increases, the perceived purchasing cost and risk of purchasing clothing will also increase. The partial correlation coefficient of two variables of age and perceived use cost was 0.0041 , and the significant probability was $0.063(>0.05)$. It showed that there was no significant correlation between the perceived use cost and age, after eliminating the two variables of "cultural level" and "income". 


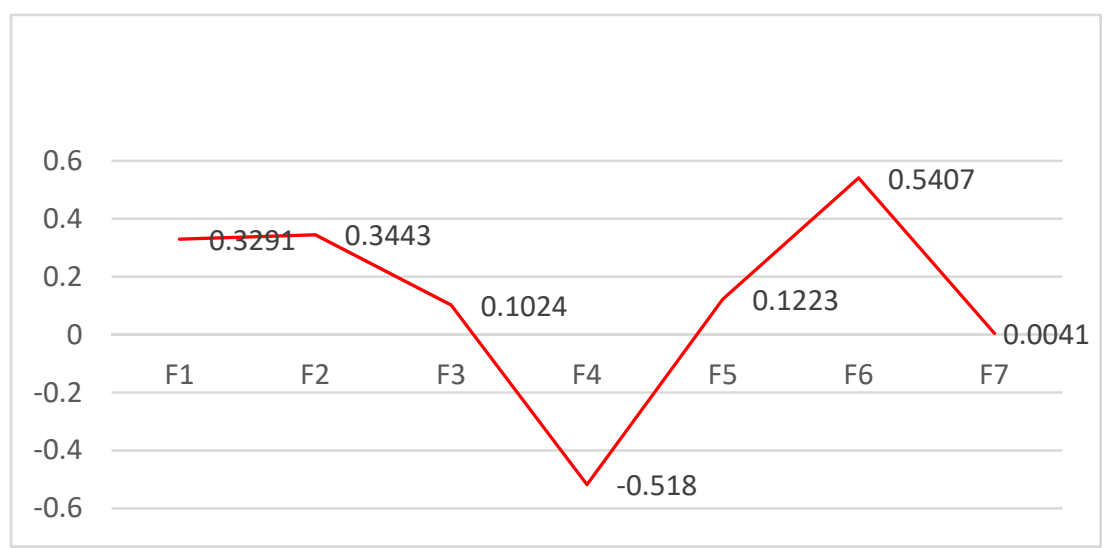

Figure 1. Correlation coefficient of "age" and "Fi"

\subsection{The Relationship between Culture and Perceived Value}

Consumers' perceived value of clothing brand is closely related to their culture. Although all the respondents are with undergraduate degrees or above, their perception of clothing brand value varies from cultural level to subtle differences. The following table is the proportion of samples at all cultural levels.

Table 3. The proportion of samples at each cultural level

\begin{tabular}{cccc}
\hline Cultural Level & Undergraduate & Master & Doctor \\
\hline Number & 329 & 194 & 17 \\
Proportion & $60.93 \%$ & $35.93 \%$ & $3.15 \%$ \\
\hline
\end{tabular}

The correlation between culture and perceived value was analyzed by SPSS19.0. The following table is a summary of the results of each factor analysis of cultural level and customer perceived value. In order to avoid the influence of other personal characteristics, two variables of "age" and "income" were eliminated in the analysis, and the partial correlation analysis of the two variables of "cultural level" and "Fi" was carried out in the double tail test.

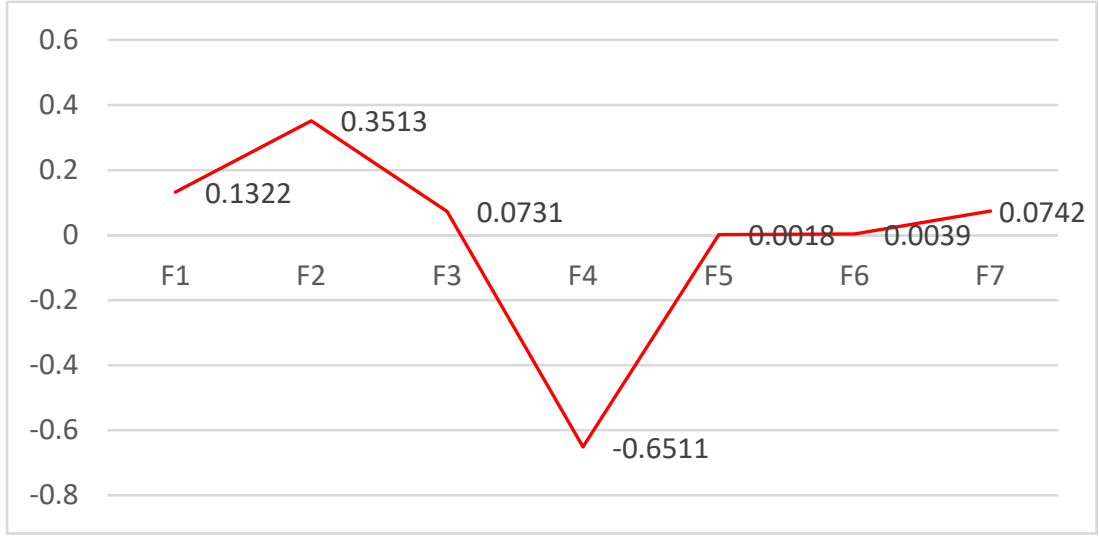

Figure 2. The correlation coefficient between "culture" and "Fi"

According to the absolute value of Pearson correlation coefficient, "0-0.09 means no correlation, 0.1-0.3 means weak correlation, 0.3-0.5 means medium correlation, 0.5-1.0 means strong correlation", and through T-test to get probability. "P<0.05 means statistical difference, $\mathrm{P}<0.01$ means significant statistical difference, $\mathrm{P}<0.001$ means extremely significant statistical difference. The correlation and significant probability of "culture" and "Fi" were analyzed. The absolute values of the correlation coefficients were $0.1322,0.3517,0.0731,0.6511,0.0018$, 0.0039 and 0.0742 , respectively. The significant probability was $0.043,0.005,0.054,0,0.121,0.062,0.070$, respectively. From the data of Figure 2, there is a weak positive correlation between "culture" and functional value (F1), the significant positive correlation between "culture" and social value (F2), the significant negative correlation between "culture" and epistemic value (F4), and no significant correlation between "culture" and F3, F5, F6, or F7. 


\subsection{The Relationship between Income and Perceived Value}

There is a great relationship between consumer buying behavior and personal income. Therefore, the perception of the value of the clothing brand must be related to their income. So the different income level may effect the importance of the perceived value, and the following cor-relational analyses reflect their attitude to each dimension. The income level and proportion are as follows.

Table 3. The proportion of monthly income (Unit: Yuan)

\begin{tabular}{ccccc}
\hline Monthly Income & 8000 and below & $8001-12000$ & $12000-20000$ & 20000 and above \\
\hline Number & 108 & 240 & 116 & 76 \\
Proportion & $20.00 \%$ & $44.44 \%$ & $21.48 \%$ & $14.07 \%$ \\
\hline
\end{tabular}

SPSS 19.0 is used to analyze the correlation between "income" and perceived value. The following table summarizes the cor-relational analysis results between individual income and perceived value. In order to avoid the influence of other personal characteristics, two variables of "age" and "cultural level" were eliminated in the analysis, and the partial correlation analysis of the two variables of "personal income" and "Fi" was carried out in the double tail test.

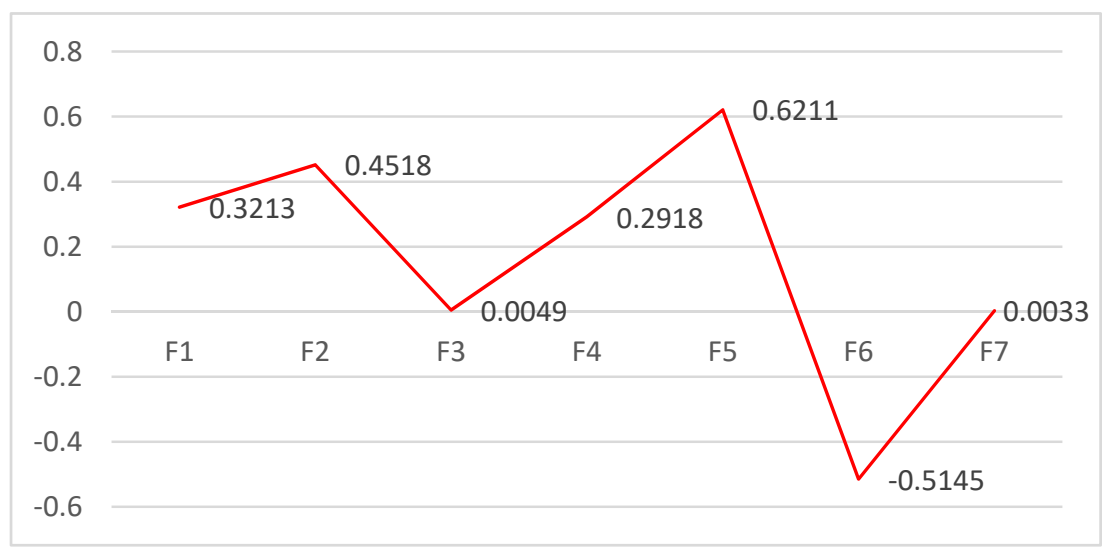

Figure 3. The correlation coefficient between "income" and "Fi"

The absolute values of the correlation coefficient between "personal income" and "Fi" were $0.3213,0.4518$, $0.0049,0.2918,0.6211,0.5145$ and 0.0033 respectively. And the significant probabilities were $0.013,0,0.114$, $0.075,0.008,0.006$, and 0.0033 respectively. According to the correlation coefficient and the standard of significant probability, the data of Figure 3 show that: the personal income and functional value (F1) have moderate positive correlation. The personal income have a significant positive correlation with social value (F2), have a weak positive correlation with epistemic value (F4), have a extremely significant positive correlation with experience value (F5), have a significant negative correlation with purchase cost and the risk (F6). There was no significant correlation between "personal income" and "F3", or between "personal income" and "F7".

\section{Conclusions}

With the development of economy and the transformation of society, people's own economic needs and social needs are constantly satisfied, so they begin to pursue higher demands. Similarly, people's demand for clothing is no longer satisfied with the low level of demand, such as physiology and security. They want to express their own uniqueness and life attitude by dress. The 80 's are the first generation with the opening of China's reform and the growth of the market economy. It is also a generation with the globalization of information and the growing up of the Internet. Their consumption concept, life style, and the value demands of apparel brands are quite different from others. On the one hand, they choose to consume clothing to get the pleasure of possessive matter. On the other hand, they want to show their own taste with dressing, prove their own culture literate, spread the culture and avant-garde of personal consumption, in order to express their own personality.

Through the research of this article, it is shown that: (1) when the intellectual 80's women of Hangzhou choose apparel brand, they pay more attention to the function of clothing, the social character of brand and popularity. Secondly, the cost that need to be paid are also the important things. (2) Through partial correlation analysis and $\mathrm{T}$ test, it was found that the individual characteristics (age, culture and income) of the intellectual 80's women were significantly different from those of the perceived values. On the one hand, with the growth of age, they tend to be rational about apparel brand consumption. The older consumers are more willing to spend more time 
and energy to avoid buying inappropriate clothes, and at the same time, the high age consumers also pay more attention to the social image of the apparel brand. However, with the increase of age, their pursuit and attempt on new things will be relatively lower. On the contrary, the younger consumers are more willing to accept new things and show a willingness to try out new style and new brands. On the other hand, with the improvement of cultural level, consumers' demand for the brand image of the apparel brand has increased, while the demand for fashion has weakened. Moreover, with the increase of income, they are more free in the choice of apparel brands and they are willing to pay higher costs, but also want to get more and better service.

In summary, in order to clearer the consumer demand, it is very necessary to discuss how to grasp the target market accurately and subdivision. Therefore, in the market environment with diversified demand, enterprises should follow the concept of 'brand driving with the core of consumer demand', understand the value orientation and demand of the target group from the perspective of consumers, and then guide the consumption to maximize the value of the clothing brand.

\section{Acknowledgments}

The authors would like to thank Donghua University, and Jiaxing University. Also, many thanks for the supporting of the project of Scientific research project of Zhejiang Education Department (00717030AW) the project of Special subject for reform and innovation of Talent Cultivation Mode of JiaXing University, the project of Cultural research project of Zhejiang Provincial Department of Culture (ZW2018045) and the project of Civil affairs policy theory research of Zhejiang Civil Affairs Bureau (ZMJF201810). Meanwhile, thanks to the editor and the readers of Asian Social Science.

\section{References}

Cang, P., \& Cai, W. (2008). The Empirical Study on the Model of Fashion Marketing Strategy and the Comprise of Brand Equity. Journal of Donghua University (Natural Scince), 32(4), 496-500. https://doi.org/10.3969/j.issn.1671 -0444.2008.04.024

Gronroos. (1997). Value-driven relational marketing: from products to resources and competences. Journal of Marketing Management, 13, 407-419. https://doi.org/10.1080/0267257X.1997.9964482

Holbrook, M. B. (1996). Special session summary: customer value - a framework for analysis and research. Advances in consumer research, (23), 138-140.

Indra jlt sinha, \& Wayne, S. (1998). An Integrated Approach toward the Spatial Modeling of Perceived Customer Value. Journal of Marketing Research, 236-249. https://doi.org/10.2307/3151851

Jiangna, Y., \& Faliang, T. (2009). The Empirical Analysis of Perceived Values of Mid-range Female Garment Customers. China Market, 19, 115-117. https://doi.org/10.3969/j.issn.1005-6432.2009.19.045

Jilian, S. C., \& Soutar. (2001). Customer perceived value: the development to a multiple item scale. Journal of Retailing, 77(2), 203-220. https://doi.org/10.1016/S0022-4359(01)00041-0

Jung, J., \& Sung, E. Y. (2008). Consumer-based brand equity: Comparisons among Americans and South Koreans in the USA and South Koreans in Korea. Journal of Fashion Marketing and Management, 12, 24-35. https://doi.org/10.1108/13612020810857925

Kotler, P., \& Gary, A. (2000). Principles of Marketing (8th ed.). Upper Saddle River, NJ: Prentiee Hall.

Lassar, W., Mittal, B., \& Sharma, A. (1995). Measuring customer-based brand equity. Journal of Consumer Marketing, (4), 11-19. https://doi.org/10.1108/07363769510095270

Parasueaman. (2000). Reflections on gaining competitive advantage trough customer value. Journal of the Academy of Marketing Seienee, 25(2).

Pengde, T., Guocai, W., \& Yanhui, Z. (2009). An empirical study on the influence of the perceived value of the retailer's private brand on the purchase intention. Social Sciences in Nanjing, 9, 40-45. https://doi.org/10.3969/j.issn.1001-8263.2009.09.007

Sheth, J., Newman, B., \& Gross, B. (1991). Consumption Values and Market Choices-Theory and Applications. Cincinnati: South-Western, 188-192.

Tong, X., \& Hawley, J. M. (2009). Creating brand equity in the Chinese clothing market: The effete of selected marketing activities on brand equity dimensions. Journal of Fashion Marketing and Management, 13, 566-581. https://doi.org/10.1108/13612020910991411

Tong, X., \& Hawley, J. M. (2009). Measuring customer-based brand equity: Empirical evidence from the sports 
wear market in China. Journal of Product \& Brand Management, 18, $262-271$. https://doi.org/10.1108/10610420910972783

Xiaoyan, Y., \& Gujin, Z. (2006). Green Value: A New Dimension of Customer Perceived Values. China Industrial Economics, (7), 110-116. https://doi.org/10.3969/j.issn.1006-480X.2006.07.015

Xiucheng, F., \& Haicheng, L. (2003). Study on Competitiveness of Service Firms: A Customer Perceived Value Perspective. Nankai Business Review, 6, 41-45. https://doi.org/10.3969/j.issn.1008-3448.2003.06.009

\section{Copyrights}

Copyright for this article is retained by the author(s), with first publication rights granted to the journal.

This is an open-access article distributed under the terms and conditions of the Creative Commons Attribution license (http://creativecommons.org/licenses/by/4.0/). 